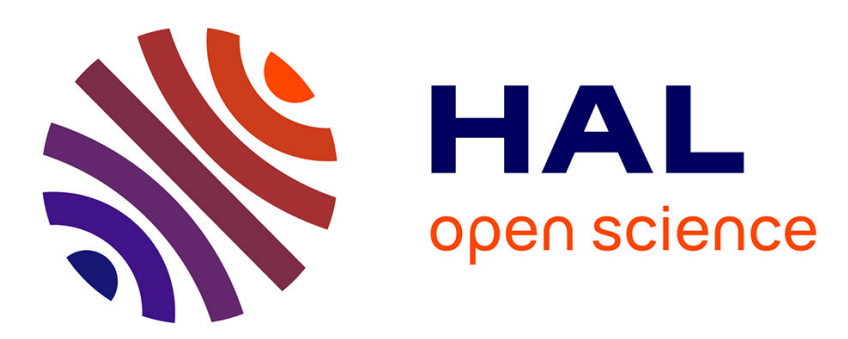

\title{
Wettability-enabling coating on oxide particles through controlled milling
}

Jean-Marc Auger, Sylvain Martin, Frédéric Gruy

\section{To cite this version:}

Jean-Marc Auger, Sylvain Martin, Frédéric Gruy. Wettability-enabling coating on oxide particles through controlled milling. Powder Technology, 2019, 344, pp.302 à 306 . 10.1016/j.powtec.2018.12.031 . hal-01951135

\section{HAL Id: hal-01951135 \\ https://hal.science/hal-01951135}

Submitted on 11 Dec 2018

HAL is a multi-disciplinary open access archive for the deposit and dissemination of scientific research documents, whether they are published or not. The documents may come from teaching and research institutions in France or abroad, or from public or private research centers.
L'archive ouverte pluridisciplinaire HAL, est destinée au dépôt et à la diffusion de documents scientifiques de niveau recherche, publiés ou non, émanant des établissements d'enseignement et de recherche français ou étrangers, des laboratoires publics ou privés. 


\title{
Wettability-enabling coating on oxide particles through controlled milling
}

\author{
J. M. Auger ${ }^{\mathrm{a}}$, S. Martin ${ }^{\mathrm{a}, *}$, F. Gruy ${ }^{\mathrm{a}}$ \\ ${ }^{a}$ Ecole des Mines de Saint-Etienne, SPIN, CNRS 530\%, LGF, F-42023 Saint-Etienne
}

\begin{abstract}
The purpose of this paper is to describe a metal deposition process which aims at getting a wettability-enhancing tin coating on silica particles. This original mechano-synthesis protocol allows the deposition of thin $(\mathrm{nm})$ metal layer on oxide, while maintaining particles integrity. Macroscopic wettability tests in liquid tin/bismuth alloy confirm the efficiency of this approach for the production of metal matrix/oxide inclusions composites, while microscopic imaging have shown that individual wetting of particles can easily be attained with the appropriate mixing conditions.
\end{abstract}

Keywords:

Liquid metal, Wetting, Silica, Mechanical coating, Milling, Tin alloy

\section{Introduction}

The insertion of oxide particles in liquid metal meets different applications like production of metal-ceramic composites ( by infiltration process [1] or mixing oxide particles within molten metal [2] ). Such a system can also be used as a starting point to study the agglomeration of oxide inclusions within

\footnotetext{
*E mail address: sylvain.martin@emse.fr
} 
liquid metal [3]. However, the difference in chemical nature between metal and oxide leads to high surface energy which means poor wettability [4]. Hence, several methods have been developed to modify wetting properties and more specifically enhance wetting in liquid metals :

- surfactant addition: introduction of magnesium in molten aluminium to allow alumina, silicon carbide, or graphite particles wetting ([5], 6], [7], [8]),

- physical/chemical alteration ([9]-thermal treatment case) of particles surface,

- mixing with a metallic alloy ([10], [11, [12]),

- in-situ coating through chemical reaction during liquid/solid contact (called reactive wetting [13])

- metallic pre-coating [14] of powders, which is the less material-specific of these approaches, and which is the purpose of this paper.

Although technologies such as sputtering or chemical deposition [15] are widely used in coating processes, they suffer from some drawbacks (slow production rate and chemical contamination for example), and from a lack of generality. They are indeed designed for specific materials and valid within a limited range of properties, such as melting point or chemical reactivity.

Thus, the aim of this study is to assess the potential of milling process, which is closed to the silica-stearate dry coating process [16], to get a soft metal coating and allow the dispersion of ceramic particles into liquid metal. This paper first presents the materials used for the study and introduce the 
original mechanical-synthesis process which allows the coating of hard oxide particles with soft metals. The surface layer is then analyzed. Finally, the coated particles are dispersed within liquid alloy to confirm the potential of this method for the production of metal/ceramic composites. The procedure will be shown with the $\mathrm{Sn} / \mathrm{Bi} / \mathrm{SiO}_{2}$ composite. This physico-chemical system has been selected as it will be subsequently used for the study of particle agglomeration dynamics at high temperature.

\section{Materials}

The oxide powder is a Geltech silica powder. It is composed of monodisperse silica spheres of $1.5 \mu \mathrm{m}$ diameter Figure 1. This powder meets the requirements to ensure both sufficient hardness to avoid damage during milling, and very low chemical reactivity at the considered temperatures. Coating metal is pure tin (99.99\%). It was chosen for its chemical similarity with the alloy used for wetting tests and its ductility. The selected tin source consists of Alfa Aesar $5 \mathrm{~mm}$ granules. The alloy, used for dispersion experiments of coated particles, is the tin/bismuth eutectic (commercial name CERROTRU from Metaconcept, $43 w \% \mathrm{Sn}$, henceforth noted $\mathrm{Sn} / \mathrm{Bi}$ ), its main advantage being its low melting point $(412 K)$.

\section{Coating process}

Coating was carried out with a planetary mill (PM400 from Retsch). A small alumina jar (50 $\mathrm{mm}$ diameter) was used as a container. The milling load was composed of $50 \mathrm{~g}$ of alumina balls: two large spheres $(20 \mathrm{~mm}$ 


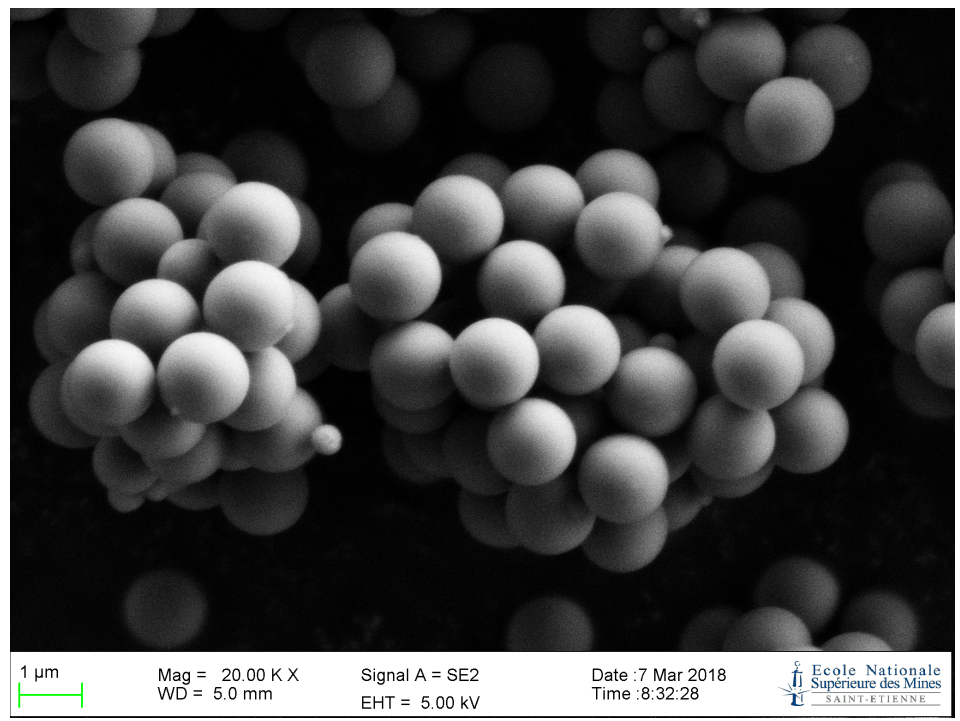

Figure 1: Silica powder before coating (SEM)

diameter) and smaller ones $(10 \mathrm{~mm})$. A static atmosphere of pure argon was used to limit tin oxidation during the whole process.

Jar and balls were carefully cleaned between each experiment, using the following procedure:

- separate rinsing of balls and jar with distilled water,

- ultrasonic bath cleaning (5 min),

- distilled water rinsing and tissue wiping,

- ethanol final rinsing.

The coating process is shown at Figure 2. It is divided into two steps:

1. Tin milling step, with $5 \mathrm{~g}$ tin granules (1/10 granules/milling balls ratio) inside the jar, carried out at $300 \mathrm{rpm}$ for 1 hour. Following 
this high energy milling, it appears that jar and balls are covered by a visible tin layer, and tin granules are highly strained (up to become spherical).

2. The coating step: $5 g$ of silica powder is added to the jar, and milled at $150 \mathrm{rpm}$ during $15 \mathrm{~min}$. At the end of this step, the balls and the jar surface are partially cleaned, while the color of silica powder have changed from white to grey. The aim of this low energy milling is to coat the powder without damaging (breakage) silica particles.

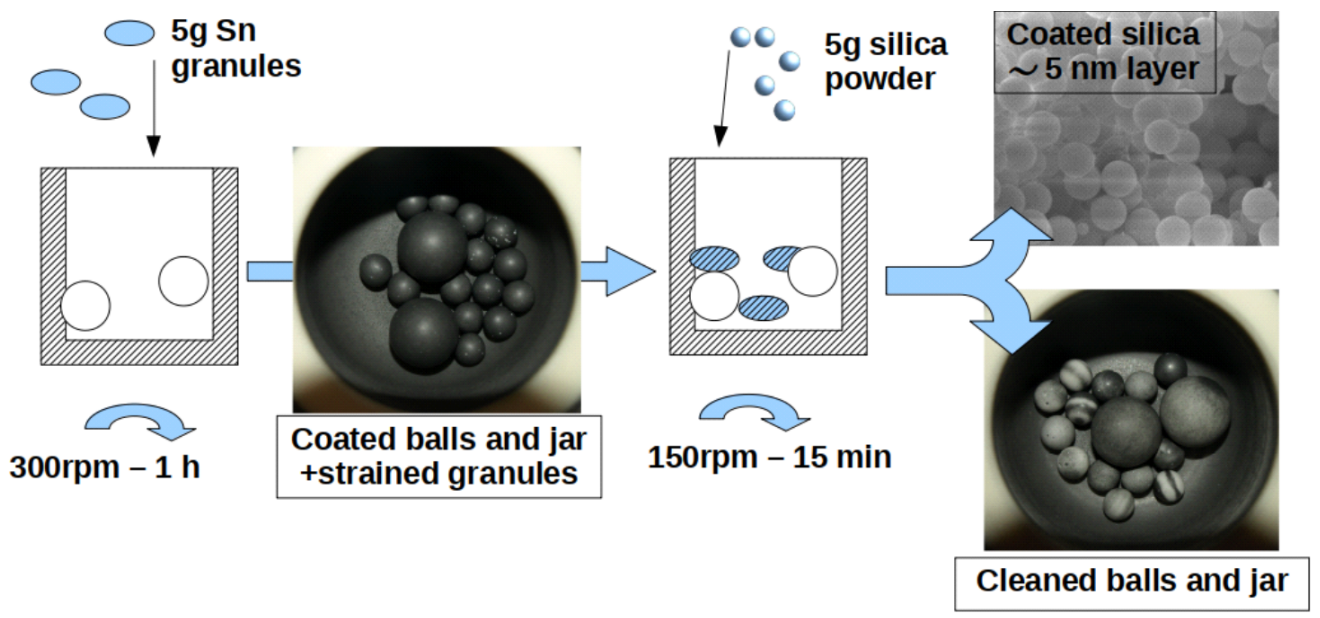

Figure 2: Coating process

Several analyses were carried out to determine the precise nature of deposited layer :

- SEM observations shown at Figure 3 revealed that coated silica powder incurred only minimal damage during the process. It should be noticed that the tin layer is not visible on the images. It can be explained easily by the very small thickness of the tin layer. 


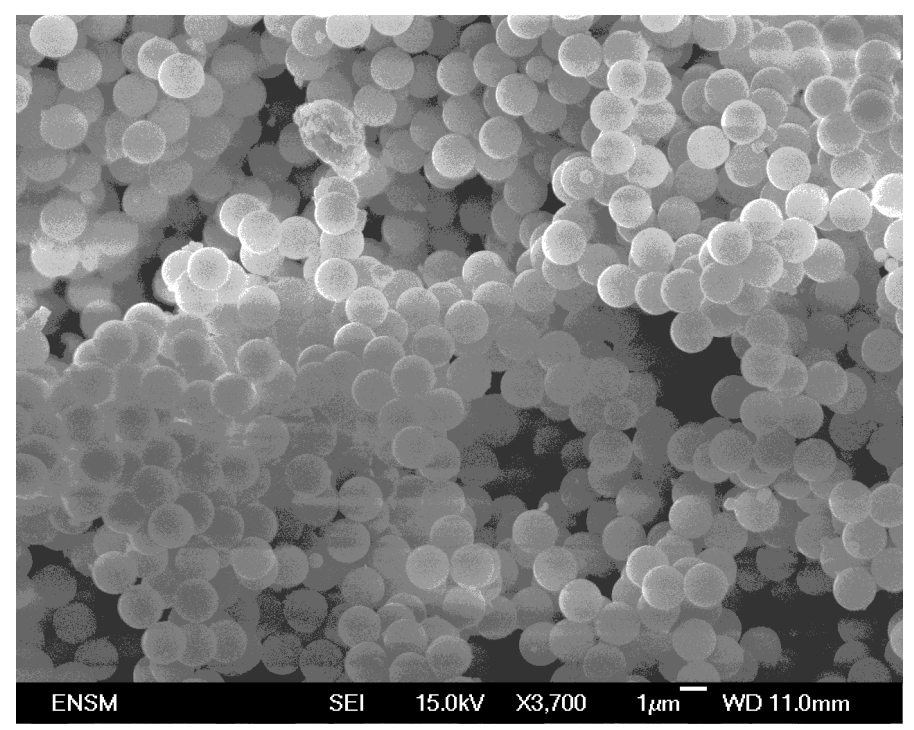

Figure 3: Silica powder after coating (SEM)

- Figure 4 compares the diffractograms of the pure amorphous silica with the coated silica produced in this work. The tin layer obtained is mostly metallic as shown by the sharp peaks due to crystalline tin. We may also observe beside the broad signal of amorphous silica, some wider peaks that indicate the presence of small crystalline domains of tin oxide

- Quantitative measurements of tin content were obtained by means of atomic emission spectroscopy (ICP-AES). Samples were prepared by complete dissolution of tin surface layer in concentrated (38wt\%) hydrochloric acid ( $0.2 \mathrm{~g}$ of coated powder for $2 \mathrm{~mL}$ acid); solutions were then diluted with $12 \mathrm{~mL}$ water and analyzed, leading to measurement of tin concentration (20 ppm precision). Assuming an homogeneous layer at the surface of particles, the tin thickness can be estimated : 


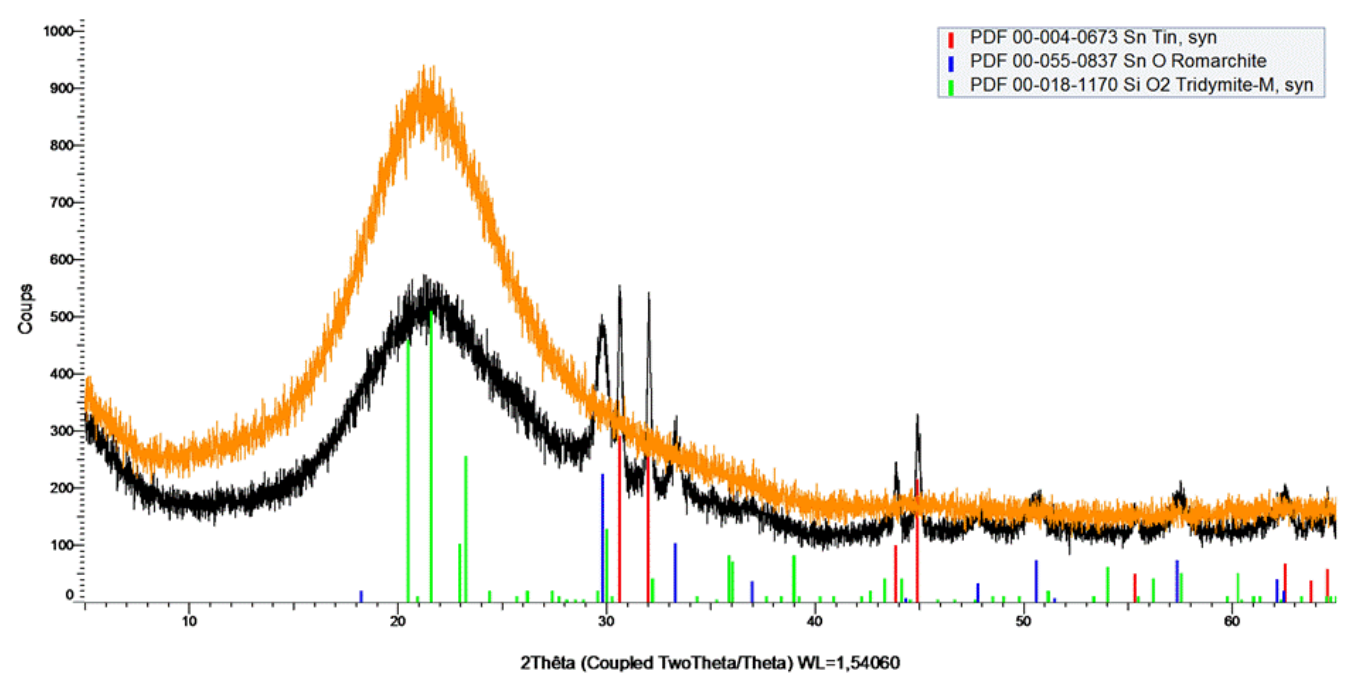

Figure 4: Diffractograms of pure amorphous silica (orange) and coated silica (black)

$3 \mathrm{~nm}$. This result was further confirmed by XPS analysis, which leads to an estimation (using simple models for flat layers instead of spheres) of the tin layer thickness smaller than $5 \mathrm{~nm}$. Thus, this result confirms the assumption that the tin layer is not visible on SEM images because of its very small thickness.

\section{Wettability testing}

Considering the final aim of our work which was to reach a full dispersion of ceramic particles within liquid metal, it was decided to evaluate the coating effect by directly studying the ability of coated powder to be introduced within liquid metal.

Hence, $5 \% \mathrm{vol}$. of coated powders were added (over a $20 \mathrm{~min}$ duration) to liquid metal $\left(300 \mathrm{~g}\right.$ stirred $\mathrm{Sn} / \mathrm{Bi}$ alloy at $\left.200^{\circ} \mathrm{C}\right)$. The resulting slurry 
was then cast into cylindrical ingots. Ingots were then cross-sectioned and observed through electron microscopy.

For comparison purposes, coated and uncoated powders were introduced within liquid alloy at two different stirring speeds (300 and $600 \mathrm{rpm}$ ).

Experiments with either coated or uncoated silica, stirred at $300 \mathrm{rpm}$, led to the accumulation of powder at the liquid alloy surface, with no apparent wetting. This observation is confirmed by the absence of silica particles in the corresponding cross-sectioned ingots. On the other hand, coated silica mixed at $600 \mathrm{rpm}$ resulted in complete disappearance of the powder. SEM imaging of cross-sectioned alloy samples, shown at Figure 5 , indeed reveals a full wetting of silica spheres and a full contact between particles and metal matrix. The conclusion of these observations is that metallic coating of silica is a necessary condition for wetting, but is not sufficient. Hence, a direct contact between liquid metal and particles is required, and it can only be obtained with high speed stirring. It is assumed that, with this experimental setup, shearing at the surface of liquid metal is high enough to allow the breakage of the spontaneously formed oxide layer. Thus, coated silica is easily dispersed within the $\mathrm{Sn} / \mathrm{Bi}$ alloy.

\section{Conclusion}

The 2-steps coating process presented in this study is shown to be an efficient process to obtain a metallic tin layer on silica powder, with minimal damage incurred by the particles. In spite of its very low (nanometer scale) thickness, this layer is able to allow a complete wetting of oxide particles by liquid metal. The experimental conditions required to ensure direct contact 


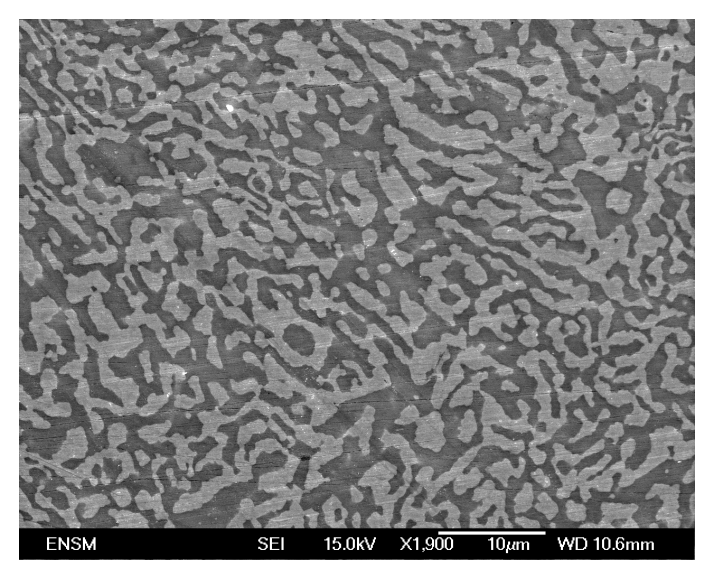

a

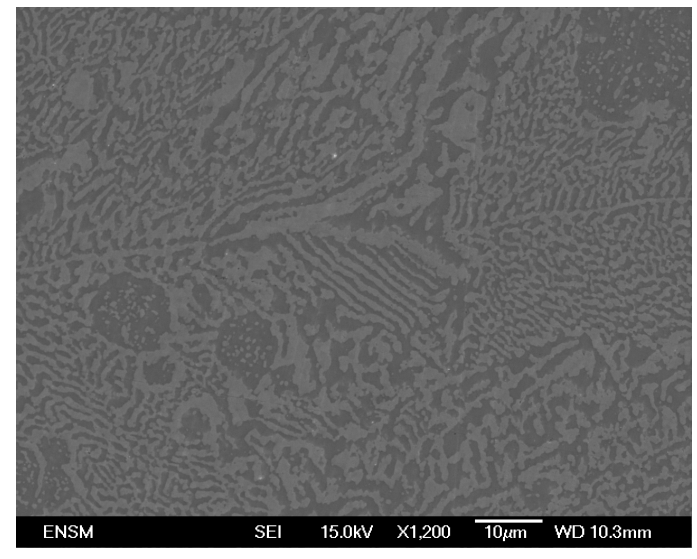

$\mathrm{C}$

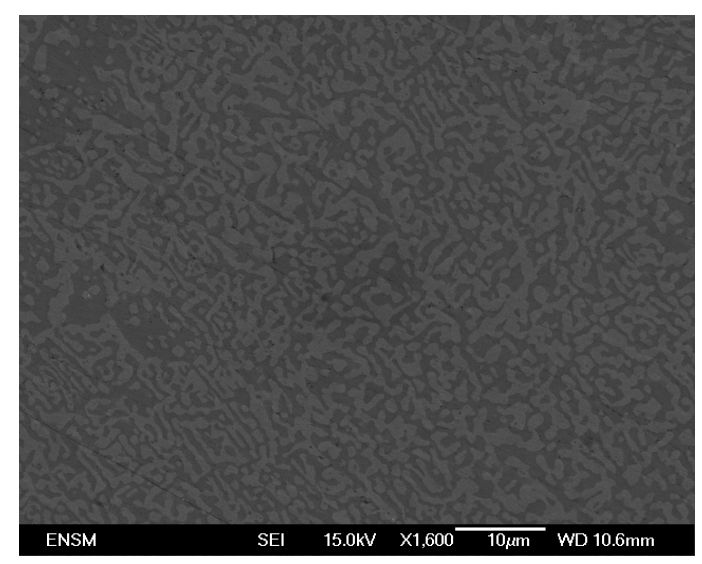

$\mathrm{b}$

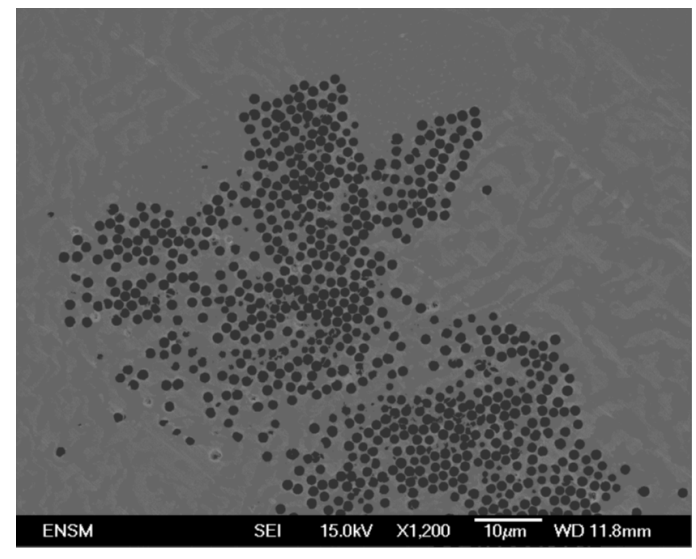

d

Figure 5: SEM images of ingots for uncoated $(\mathrm{a}, \mathrm{b})$ and coated $(\mathrm{c}, \mathrm{d})$ silica introduced at 300 (a, c) and $600 \mathrm{rpm}(\mathrm{b}, \mathrm{d})$ 
between unoxidized metal and coated particles are also provided. Obvious advantages over existing coating methods resides in protocol simplicity (no need for specialized equipment), scalability and generality (no dependency on specific chemical reactivity). Since this study was only dedicated to $\mathrm{SiO}_{2} / \mathrm{Sn}$, further works will be carried out to study the adaptability of this process to others oxide/metal couples, but it can be assumed that the main condition is the difference in hardness between oxide and metal. Potential applications range from laboratory experiments with oxide/metal couples, to cleaner and more environment friendly large scale industrial production, since this process do not involve any unwanted by-products, contrary, for example, to the chemical coating route.

\section{Aknowledgement}

This research work was carried out in the context of French/German FLOTINC project (ref. ANR-15-CE08-0040), funded by ANR (Agence Nationale de la Recherche) and DFG (Deutsche Forschungsgemeinschaft).

\section{References}

[1] A. Kennedy, J. Wood, B. Weager, The wetting and spontaneous infiltration of ceramics by molten copper, Journal of Materials Science 35 (2000) 2909-2912.

[2] A. Kennedy, A. Karantzalis, The incorporation of ceramic particles in molten aluminium and the relationship to contact angle data, Materials Science and Engineering: A 264 (1999) 122-129. 
[3] M. Cournil, F. Gruy, P. Gardin, H. Saint-Raymond, Modelling of solid particle aggregation dynamics in non-wetting liquid medium, Chemical Engineering and Processing: Process Intensification 45 (2006) 586-597.

[4] N. Eustathopoulos, M. G. Nicholas, B. Drevet, Wettability at high temperatures, volume 3, Elsevier, 1999.

[5] G. Ramani, T. Ramamohan, R. Pillai, B. Pai, Stability of non-wetting dispersoid suspensions in metallic melts, Scripta Metallurgica et Materialia 24 (1990) 1419-1424.

[6] B. Pai, G. Ramani, R. Pillai, K. Satyanarayana, Role of magnesium in cast aluminium alloy matrix composites, Journal of Materials Science 30 (1995) 1903-1911.

[7] B. Schultz, J. Ferguson, P. Rohatgi, Microstructure and hardness of al2o3 nanoparticle reinforced al-mg composites fabricated by reactive wetting and stir mixing, Materials Science and Engineering: A 530 (2011) 87-97.

[8] B. Pai, S. Ray, K. Prabhakar, P. Rohatgi, Fabrication of aluminiumalumina (magnesia) particulate composites in foundries using magnesium additions to the melts, Materials Science and Engineering 24 (1976) $31-44$.

[9] V. Agarwala, D. Dixit, Fabrication of aluminium base composite by foundry technique, Transactions of the Japan Institute of Metals 22 (1981) 521-526. 
[10] S. Tahamtan, A. Halvaee, M. Emamy, M. Zabihi, Fabrication of al/a206al2o3 nano/micro composite by combining ball milling and stir casting technology, Materials \& Design 49 (2013) 347-359.

[11] B. C. Pai, P. Rohatgi, Production of cast aluminium-graphite particle composites using a pellet method, Journal of Materials Science 13 (1978) $329-335$.

[12] S. Amirkhanlou, B. Niroumand, Fabrication and characterization of al356/sicp semisolid composites by injecting sicp containing composite powders, Journal of Materials Processing Technology 212 (2012) 841847.

[13] E. Saiz, R. M. Cannon, A. P. Tomsia, Reactive spreading in ceramic/metal systems, Oil \& Gas Science and Technology 56 (2001) 89-96.

[14] F. Badia, P. Rohatgi, Dispersion of graphite particles in aluminum castings through injection of the melt (1969).

[15] E. Matijevic, A. Poskanzer, P. Zuman, Characterization of the stannous chloride/palladium chloride catalysts for electroless plating, Plating and Surface Finishing 62 (1975) 958-965.

[16] Y. Ouabbas, A. Chamayou, L. Galet, M. Baron, G. Thomas, P. Grosseau, B. Guilhot, Surface modification of silica particles by dry coating: Characterization and powder ageing, Powder Technology 190 (2009) 200 - 209. Selection of Papers from the Symposium Powder Science and Technology - Powders and Sintered Material STP-PMF 2007. 